\title{
Toxicity assessment of hydrogen peroxide on Toll-like receptor system, apoptosis, and mitochondrial respiration in piglets and IPEC-J2 cells
}

\author{
Jie Yin ${ }^{1,2, *}$, Miaomiao Wu ${ }^{1, *}$, Yuying Li ${ }^{1,2, *}$, Wenkai Ren ${ }^{1,2}$, Hao Xiao ${ }^{1}$, Shuai Chen ${ }^{1,2}$, \\ Chunyong Li ${ }^{1}$, Bie Tan ${ }^{1}$, Hengjia Ni ${ }^{1}$, Xia Xiong ${ }^{1}$, Yuzhe Zhang ${ }^{1}$, Xingguo Huang ${ }^{3,4}$, \\ Rejun Fang ${ }^{3}$, Tiejun $\mathrm{Li}^{1,4}$, Yulong Yin ${ }^{1,4,5}$ \\ ${ }^{1}$ Scientific Observing and Experimental Station of Animal Nutrition and Feed Science in South-Central, Ministry of Agriculture, \\ Hunan Provincial Engineering Research Center of Healthy Livestock, Key Laboratory of Agro-ecological Processes in \\ Subtropical Region, Institute of Subtropical Agriculture, Chinese Academy of Sciences, Changsha, Hunan 410125, China \\ ${ }^{2}$ University of Chinese Academy of Sciences, Beijing 100039, China \\ ${ }^{3}$ Department of Animal Science, Hunan Agriculture University, Changsha, Hunan 410125, China \\ ${ }^{4}$ Hunan Co-Innovation Center of Animal Production Safety, Changsha, Hunan 410128, China \\ ${ }^{5}$ College of Animal Science of South China Agricultural University, Guangzhou 510642, China \\ *These authors contributed equally to this work
}

Correspondence to: Tiejun Li, email: tjli@isa.ac.cn Yulong Yin, email: yinyulong@isa.ac.cn

Keywords: $\mathrm{H}_{2} \mathrm{O}_{2}$,TLRs, apoptosis, mitochondrial respiration, piglet

Received: September 28, $2016 \quad$ Accepted: November 24, $2016 \quad$ Published: December 09,2016

\section{ABSTRACT}

In this study, expressions of toll-like receptors (TLRs) and apoptosis-related genes in piglets and mitochondrial respiration in intestinal porcine epithelial cells were investigated after hydrogen peroxide $\left(\mathrm{H}_{2} \mathrm{O}_{2}\right)$ exposure. The in vivo results showed that $\mathrm{H}_{2} \mathrm{O}_{2}$ influenced intestinal expressions of TLRs and apoptosis related genes. $\mathrm{H}_{2} \mathrm{O}_{2}$ treatment (5\% and $10 \%)$ downregulated uncoupling protein 2 (UCP2) expression in the duodenum $(P<0.05)$, while low dosage of H2O2 significantly increased UCP2 expression in the jejunum $(P<0.05)$. In IPEC-J2 cells, $\mathrm{H}_{2} \mathrm{O}_{2}$ inhibited cell proliferation $(P<0.05)$ and caused mitochondrial dysfunction via reducing maximal respiration, spare respiratory, non-mitochondrial respiratory, and ATP production $(P<0.05)$. However, 50 uM $\mathrm{H}_{2} \mathrm{O}_{2}$ significantly enhanced mitochondrial proton leak $(P<0.05)$. In conclusion, $\mathrm{H}_{2} \mathrm{O}_{2}$ affected intestinal TLRs system, apoptosis related genes, and mitochondrial dysfunction in vivo and in vitro models. Meanwhile, low dosage of $\mathrm{H}_{2} \mathrm{O}_{2}$ might exhibit a feedback regulatory mechanism against oxidative injury via increasing UCP 2 expression and mitochondrial proton leak.

\section{INTRODUCTION}

Hydrogen peroxide $\left(\mathrm{H}_{2} \mathrm{O}_{2}\right)$, a highly reactive oxygen species (ROS), is associated with the imbalance of cellular redox in vivo and in vitro [1-4], which further induces oxidative stress and leads to irreparable oxidative injury. Various stressors have been linked to oxidative stress, such as birth process, weaning, mycotoxins contamination, and inflammatory response [5-8]. $\mathrm{H}_{2} \mathrm{O}_{2}$ causes a significant disruption in the oxidative balance evidenced by the decreased serum antioxidant enzymes and increased malondialdeyhde levels in various models [9-12]. However, the toxic effects of $\mathrm{H}_{2} \mathrm{O}_{2}$ on Toll-like receptors (TLRs), apoptosis, and mitochondrial respiration in piglet model are still obscure. Thus, in this study, piglet model and intestinal porcine epithelial cells (IPEC-J2) were used to test the toxic effects of $\mathrm{H}_{2} \mathrm{O}_{2}$ on TLRs system, apoptosis, and mitochondrial respiration.

\section{RESULTS}

Effect of $\mathrm{H}_{2} \mathrm{O}_{2}$ on intestinal TLRs system in piglets

In the duodenum, $10 \% \mathrm{H}_{2} \mathrm{O}_{2}$ significantly inhibited TLR2 expression $(p<0.05)$. Compared with the control group, low dosage of $\mathrm{H}_{2} \mathrm{O}_{2}(5 \%)$ markedly upregulated TLR4 and TLR5 expression $(p<0.05)$, while $10 \% \mathrm{H}_{2} \mathrm{O}_{2}$ inhibited TLR4 and TLR7 expression compared with 5\% 
$\mathrm{H}_{2} \mathrm{O}_{2}$ (Table 1) $(p<0.05)$. In the jejunum, low dosage of $\mathrm{H}_{2} \mathrm{O}_{2}(5 \%)$ upregulated TLR1, TLR2, TLR4, TLR7, TLR10, and Myd88 expressions compared with the control group ( $p$ $<0.05$ ), while the expression of TLR1, TLR3, TLR4, TLR5, TLR6, and Myd88 in the $10 \% \mathrm{H}_{2} \mathrm{O}_{2}$ group were significantly lower than that in the low dosage of $\mathrm{H}_{2} \mathrm{O}_{2}(5 \%)$ group ( $p<$ 0.05 ) (Table 2). In the ileum, $\mathrm{H}_{2} \mathrm{O}_{2}$ exposure significantly inhibited TLR2 and TLR 5 expression $(p<0.05)$ (Table 3$)$.

\section{Effect of $\mathrm{H}_{2} \mathrm{O}_{2}$ on intestinal apoptosis related genes in piglets}

In the duodenum, low dosage of $\mathrm{H}_{2} \mathrm{O}_{2}(5 \%)$ significantly increased Casp8 expression compared with the control group, while high dosage of $\mathrm{H}_{2} \mathrm{O}_{2}(10 \%)$ inhibited Casp8 expression compared with the low dosage of $\mathrm{H}_{2} \mathrm{O}_{2}(5 \%)$ treatment $(p<0.05)$. In the jejunum, the mRNA abundance of Fasl, Casp8, and p53 were markedly increased in the low dosage of $\mathrm{H}_{2} \mathrm{O}_{2}(5 \%)$ group compared with the control group $(p<0.05)$, while high dosage of $\mathrm{H}_{2} \mathrm{O}_{2}(10 \%)$ exposure significantly downregulated Fasl, Casp8, Bcl-2, and p53 expression $(p<0.05)$. In the ileum, $\mathrm{H}_{2} \mathrm{O}_{2}$ exposure inhibited Fasl, Casp3, Casp8, and Bcl-2 expression ( $p<0.05)$ (Table 4).

\section{Effect of $\mathrm{H}_{2} \mathrm{O}_{2}$ on intestinal $\mathrm{UCP} 2$ expression in piglets}

In the duodenum, $5 \%$ and $10 \% \mathrm{H}_{2} \mathrm{O}_{2}$ administration markedly decreased UCP2 expression compared with the control group. In the jejunum, low dosage of $\mathrm{H}_{2} \mathrm{O}_{2}$ (5\%) treatment upregulated UCP2 expression, while high dosage of $\mathrm{H}_{2} \mathrm{O}_{2}(10 \%)$ treatment reduced UCP2 upregulation compared with low dosage of $\mathrm{H}_{2} \mathrm{O}_{2}(5 \%)$ treatment $(p<0.05)$ (Figure 1).

\section{Effect of $\mathrm{H}_{2} \mathrm{O}_{2}$ on cell proliferation in IPEC-J2 cells}

As shown in Figure 2A, $\mathrm{H}_{2} \mathrm{O}_{2}(100,200,250,300$, 400 , and $500 \mathrm{uM}$ ) significantly inhibited cell viability. The results from EdU assay also showed that $\mathrm{H}_{2} \mathrm{O}_{2}$ $(50,100$, and $200 \mathrm{uM})$ exposure significantly reduced cell proliferation (Figure 2B and 2C).

\section{Effect of $\mathrm{H}_{2} \mathrm{O}_{2}$ on cell mitochondrial respiration in IPEC-J2 cells}

The working model of mitochondrial respiration determination was shown at Figure $3 \mathrm{~A}$ and $3 \mathrm{~B}$. The results showed that $\mathrm{H}_{2} \mathrm{O}_{2}$ decreased mitochondrial basal OCAR (Figure 3C), maximal respiration (Figure 3E), spare respiratory (Figure $3 \mathrm{~F}$ ), non-mitochondrial respiratory (Figure 3G), and ATP production (Figure 3H) in a dosagedependent manner. Interestingly, $50 \mathrm{uM} \mathrm{H}_{2} \mathrm{O}_{2}$ significantly increased mitochondrial proton leak compared with the control group (Figure 3D), while high dosage of $\mathrm{H}_{2} \mathrm{O}_{2}$ (200 uM) markedly inhibited mitochondrial proton leak compared with other dosage groups.

\section{DISCUSSION}

Previous studies revealed that intragastric or peritoneal injection of $\mathrm{H}_{2} \mathrm{O}_{2}$ induced inestinal oxidative stress. Meanwhile, the dysfunction of intestinal permeability, morphology, and barrier function were noticed after exposure to $\mathrm{H}_{2} \mathrm{O}_{2}$ in piglets and mice $[9,13-15]$. In this study, we further found that $\mathrm{H}_{2} \mathrm{O}_{2}$ affected inestinal expression of TLR system and apoptosis related genes in piglets and influenced mitochondrial respiration in IPEC-J2 cells.

TLRs (TLR 1-10) are expressed by various cells in the gastrointestinal tract and involve in the induction of an inflammatory response and oxidative stress [16-19]. Previous studies exhibited that $\mathrm{H}_{2} \mathrm{O}_{2}$ exposure induced intestinal oxidative stress and inflammation $[9,13$, 20, 21]. In this study, we found that low dosage of $\mathrm{H}_{2} \mathrm{O}_{2}$ (5\%) upregulated TLRs, including TLR4 and TLR5 in the duodenum and TLR1, TLR2, TLR3, TLR4, TLR7, TLR10, and $\mathrm{Myd} 88$ in the jejunum. However, high dosage of $\mathrm{H}_{2} \mathrm{O}_{2}$ $(10 \%)$ inhibited TLR2, TLR4, and TLR7 in the jejunum and TLR1, TLR3, TLR4, TLR5, TLR6, and Myd88 in the jejunum compared with the low dosage of $\mathrm{H}_{2} \mathrm{O}_{2}$ treatment. Thus, we speculated that low $\mathrm{H}_{2} \mathrm{O}_{2}$ might activate TLRs while high $\mathrm{H}_{2} \mathrm{O}_{2}$ inhibited TLRs. Meanwhile, the effect may be segmental dependent because $\mathrm{H}_{2} \mathrm{O}_{2}$ downregulated TLR2 and TLR5 expression in the ileum.

Our previous study showed that $\mathrm{H}_{2} \mathrm{O}_{2}$ exposure caused intestinal morphologic injury [9], which may associate with apoptosis. In the present study, we found that $\mathrm{H}_{2} \mathrm{O}_{2}$ treatment influenced intestinal Fasl, Casp3, Casp8, Bcl-2, and p53 expressions in piglets. This hypothesis is further confirmed by the CKK-8 and EdU assay that $\mathrm{H}_{2} \mathrm{O}_{2}$ exposure markedly inhibited cell proliferation. Apoptosis and proliferation play a crucial role in cell growth and oxidative stress [22-24].

$\mathrm{UCP} 2$ has been considered as a feedback regulatory mechanism for oxidative stress and our previous studies showed that birth and weaning-induced oxidative stress activated UCP2 to improve antioxidant function $[5,6]$. In this study, $\mathrm{H}_{2} \mathrm{O}_{2}$ exposure inhibited $\mathrm{UCP} 2$ expression in the duodenum, while low dosage of $\mathrm{H}_{2} \mathrm{O}_{2}$ upregulated UCP2. In the jejunum, low dosage of $\mathrm{H}_{2} \mathrm{O}_{2}$ enhanced UCP2 mRNA abundance, while high dosage markedly inhibited UCP2 expression. So we speculated that low dosage of $\mathrm{H}_{2} \mathrm{O}_{2}$ might exhibit a feedback regulatory mechanism against oxidative stress evidenced by upregulating UCP2 expression. Furthermore, consistent with this speculation, in vitro data suggested that low dosage of $\mathrm{H}_{2} \mathrm{O}_{2}(50 \mathrm{uM})$ markedly enhanced mitochondrial proton leak. UCP2 has been reported to increase proton leak, which further decreases ROS production and protects against oxidative stress [25]. The mitochondrial respiration assay further confirmed the feedback regulatory mechanism of low dosage of $\mathrm{H}_{2} \mathrm{O}_{2}$ against oxidative stress via increasing UCP2 expression and mitochondrial proton leak. 
Table 1: TLRs expression in the duodenum after $\mathrm{H}_{2} \mathrm{O}_{2}$ exposure

\begin{tabular}{cccc}
\hline Item & Cont & $\mathbf{5 \%} \mathbf{H}_{2} \mathbf{O}_{2}$ & $\mathbf{1 0 \%} \mathbf{H}_{2} \mathbf{O}_{2}$ \\
\hline TLR1 & $1.00 \pm 0.09$ & $1.03 \pm 0.06$ & $0.90 \pm 0.11$ \\
TLR2 & $1.00 \pm 0.06^{\mathrm{a}}$ & $0.88 \pm 0.12^{\mathrm{a}}$ & $0.49 \pm 0.06^{\mathrm{b}}$ \\
TLR3 & $1.00 \pm 0.11$ & $1.28 \pm 0.16$ & $1.07 \pm 0.09$ \\
TLR4 & $1.00 \pm 0.10^{\mathrm{b}}$ & $1.88 \pm 0.16^{\mathrm{a}}$ & $1.01 \pm 0.08^{\mathrm{b}}$ \\
TLR5 & $1.00 \pm 0.07^{\mathrm{b}}$ & $1.54 \pm 0.19^{\mathrm{a}}$ & $1.22 \pm 0.05^{\mathrm{ab}}$ \\
TLR6 & $1.00 \pm 0.10$ & $0.99 \pm 0.07$ & $1.00 \pm 0.05$ \\
TLR7 & $1.00 \pm 0.12^{\mathrm{ab}}$ & $1.25 \pm 0.14^{\mathrm{a}}$ & $0.85 \pm 0.07^{\mathrm{b}}$ \\
TLR8 & $1.00 \pm 0.16$ & $0.79 \pm 0.09$ & $0.84 \pm 0.09$ \\
TLR10 & $0.95 \pm 0.09$ & $1.14 \pm 0.08$ \\
Myd88 & $1.00 \pm 0.15$ & $1.35 \pm 0.11$ & $1.22 \pm 0.12$ \\
\hline
\end{tabular}

Data are expressed as the mean \pm standard error of the mean Values in the same row with different superscripts are significant $(P<0.05)$, while values with same superscripts are not significant different $(P>0.05)$.

Table 2: TLR expression in the jejunum after $\mathrm{H}_{2} \mathrm{O}_{2}$ exposure

\begin{tabular}{cccc}
\hline Item & Cont & $\mathbf{5 \%} \mathbf{H}_{2} \mathbf{O}_{2}$ & $\mathbf{1 0 \%} \mathbf{H}_{2} \mathbf{O}_{2}$ \\
\hline TLR1 & $1.00 \pm 0.18^{\mathrm{b}}$ & $3.83 \pm 0.41^{\mathrm{a}}$ & $1.36 \pm 0.21^{\mathrm{b}}$ \\
TLR2 & $1.00 \pm 0.10^{\mathrm{b}}$ & $2.39 \pm 0.35^{\mathrm{a}}$ & $1.74 \pm 0.18^{\mathrm{ab}}$ \\
TLR3 & $1.00 \pm 0.18^{\mathrm{a}}$ & $1.00 \pm 0.11^{\mathrm{a}}$ & $0.36 \pm 0.05^{\mathrm{b}}$ \\
TLR4 & $1.00 \pm 0.08^{\mathrm{b}}$ & $2.88 \pm 0.19^{\mathrm{a}}$ & $1.40 \pm 0.13^{\mathrm{b}}$ \\
TLR5 & $1.00 \pm 0.12^{\mathrm{ab}}$ & $1.43 \pm 0.22^{\mathrm{a}}$ & $0.86 \pm 0.15^{\mathrm{b}}$ \\
TLR6 & $1.29 \pm 0.16^{\mathrm{a}}$ & $0.58 \pm 0.09^{\mathrm{b}}$ \\
TLR7 & $1.00 \pm 0.31^{\mathrm{ab}}$ & $1.96 \pm 0.27^{\mathrm{a}}$ & $1.21 \pm 0.18^{\mathrm{ab}}$ \\
TLR8 & $1.00 \pm 0.19^{\mathrm{b}}$ & $1.68 \pm 0.23$ & $1.37 \pm 0.14$ \\
TLR10 & $1.00 \pm 0.24$ & $2.51 \pm 0.47^{\mathrm{a}}$ & $1.98 \pm 0.43^{\mathrm{ab}}$ \\
Myd88 & $1.00 \pm 0.23^{\mathrm{b}}$ & $2.58 \pm 0.69^{\mathrm{a}}$ & $0.81 \pm 0.13^{\mathrm{b}}$ \\
\hline
\end{tabular}

Data are expressed as the mean \pm standard error of the mean Values in the same row with different superscripts are significant $(P<0.05)$, while values with same superscripts are not significant different $(P>0.05)$.

Table 3: TLR expression in the ileum after $\mathrm{H}_{2} \mathrm{O}_{2}$ exposure

\begin{tabular}{cccc}
\hline Item & Cont & $\mathbf{5 \%} \mathbf{H}_{\mathbf{2}} \mathbf{O}_{\mathbf{2}}$ & $\mathbf{1 0 \%}_{\mathbf{2}} \mathbf{O}_{\mathbf{2}}$ \\
\hline TLR1 & $1.00 \pm 0.14$ & $1.00 \pm 0.14$ & $0.69 \pm 0.12$ \\
TLR2 & $1.00 \pm 0.23^{\mathrm{a}}$ & $0.73 \pm 0.06^{\mathrm{b}}$ & $0.68 \pm 0.09^{\mathrm{b}}$ \\
TLR3 & $1.00 \pm 0.25$ & $0.52 \pm 0.06$ & $0.53 \pm 0.06$ \\
TLR4 & $1.00 \pm 0.17$ & $0.52 \pm 0.05$ & $1.00 \pm 0.15$ \\
TLR5 & $1.00 \pm 0.34^{\mathrm{a}}$ & $0.42 \pm 0.06^{\mathrm{b}}$ & $0.35 \pm 0.06^{\mathrm{b}}$ \\
TLR6 & $1.00 \pm 0.25$ & $1.17 \pm 0.22$ & $1.04 \pm 0.20$ \\
TLR7 & $1.00 \pm 0.12$ & $1.24 \pm 0.13$ & $0.93 \pm 0.17$ \\
TLR8 & $1.00 \pm 0.24^{\mathrm{a}}$ & $0.40 \pm 0.05^{\mathrm{b}}$ & $0.78 \pm 0.16^{\mathrm{a}}$ \\
TLR10 & $1.00 \pm 0.32$ & $3.03 \pm 0.40$ & $2.21 \pm 0.33$ \\
Myd88 & $1.00 \pm 0.23$ & $0.82 \pm 0.17$ & $0.90 \pm 0.15$ \\
\hline
\end{tabular}

Data are expressed as the mean \pm standard error of the mean. Values in the same row with different superscripts are significant $(P<0.05)$, while values with same superscripts are not significant different $(P>0.05)$. 
Table 4: Apoptosis relative genes expression after $\mathrm{H}_{2} \mathrm{O}_{2}$ exposure

\begin{tabular}{lccccc}
\hline \multicolumn{1}{c}{ Item } & Fasl & Casp8 & Casp3 & Bcl2 & P53 \\
\hline Duodenum & & & & \\
Cont & $1.00 \pm 0.13$ & $1.00 \pm 0.10^{\mathrm{b}}$ & $1.00 \pm 0.08$ & $1.00 \pm 0.09$ & $1.00 \pm 0.07$ \\
$5 \% \mathrm{H}_{2} \mathrm{O}_{2}$ & $1.05 \pm 0.17$ & $1.96 \pm 0.27^{\mathrm{a}}$ & $1.00 \pm 0.09$ & $0.91 \pm 0.11$ & $1.28 \pm 0.17$ \\
$10 \% \mathrm{H}_{2} \mathrm{O}_{2}$ & $0.90 \pm 0.10$ & $1.32 \pm 0.12^{\mathrm{b}}$ & $0.91 \pm 0.07$ & $1.04 \pm 0.11$ & $1.28 \pm 0.12$ \\
Jejunum & & & & \\
Cont & $1.00 \pm 0.18^{\mathrm{b}}$ & $1.00 \pm 0.25^{\mathrm{b}}$ & $1.00 \pm 0.16$ & $1.00 \pm 0.17^{\mathrm{ab}}$ & $1.00 \pm 0.16^{\mathrm{b}}$ \\
$5 \% \mathrm{H}_{2} \mathrm{O}_{2}$ & $1.71 \pm 0.27^{\mathrm{a}}$ & $2.11 \pm 0.30^{\mathrm{a}}$ & $1.58 \pm 0.41$ & $1.47 \pm 0.22^{\mathrm{a}}$ & $2.42 \pm 0.36^{\mathrm{a}}$ \\
$10 \% \mathrm{H}_{2} \mathrm{O}_{2}$ & $1.12 \pm 0.16^{\mathrm{b}}$ & $0.84 \pm 0.14^{\mathrm{b}}$ & $0.83 \pm 0.16$ & $0.78 \pm 0.10^{\mathrm{b}}$ & $0.98 \pm 0.14^{\mathrm{b}}$ \\
$\mathrm{Ileam}$ & & & & \\
$\mathrm{Cont}$ & $1.00 \pm 0.26^{\mathrm{a}}$ & $1.00 \pm 0.18^{\mathrm{a}}$ & $1.00 \pm 0.17^{\mathrm{a}}$ & $1.00 \pm 0.19^{\mathrm{a}}$ & $1.00 \pm 0.09^{\mathrm{ab}}$ \\
$5 \% \mathrm{H}_{2} \mathrm{O}_{2}$ & $0.37 \pm 0.07^{\mathrm{b}}$ & $0.50 \pm 0.06^{\mathrm{b}}$ & $0.16 \pm 0.02^{\mathrm{b}}$ & $0.55 \pm 0.07^{\mathrm{b}}$ & $0.82 \pm 0.07^{\mathrm{b}}$ \\
$10 \% \mathrm{H}_{2} \mathrm{O}_{2}$ & $0.25 \pm 0.07^{\mathrm{b}}$ & $0.73 \pm 0.10^{\mathrm{ab}}$ & $0.33 \pm 0.05^{\mathrm{b}}$ & $0.60 \pm 0.09^{\mathrm{b}}$ & $1.24 \pm 0.12^{\mathrm{a}}$ \\
\hline
\end{tabular}

Data are expressed as the mean \pm standard error of the mean. Values in the same row with different superscripts are significant $(P<0.05)$, while values with same superscripts are not significant different $(P>0.05)$.

Mitochondrion not only plays a crucial role in the generation, sensing, and scavenging of ROS [26], but also tightly linked to apoptosis and proliferation. The present results showed that $\mathrm{H}_{2} \mathrm{O}_{2}$ reduced mitochondrial basal OCR, maximal respiration, spare respiratory, non-mito respiratory, and ATP production in a dosage-dependent manner in a dosage-dependent manner. Similarly, Rose et al. reported that oxidative stress induced mitochondrial dysfunction via affecting ATP-linked respiration and maximal respiratory capacity [27].

In conclusion, $\mathrm{H}_{2} \mathrm{O}_{2}$ affected intestinal TLRs system and apoptosis related genes, the effect exhibited dosage and tissue dependent. Meanwhile, $\mathrm{H}_{2} \mathrm{O}_{2}$ induced mitochondrial dysfunction. However, low dosage of
A

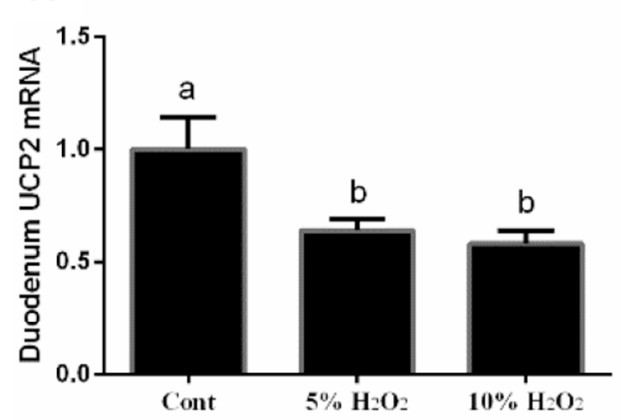

B

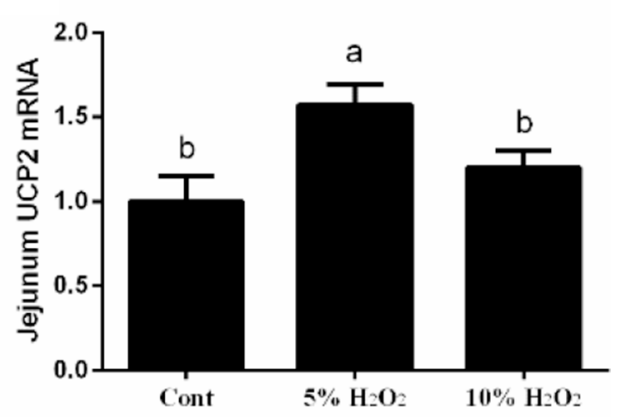

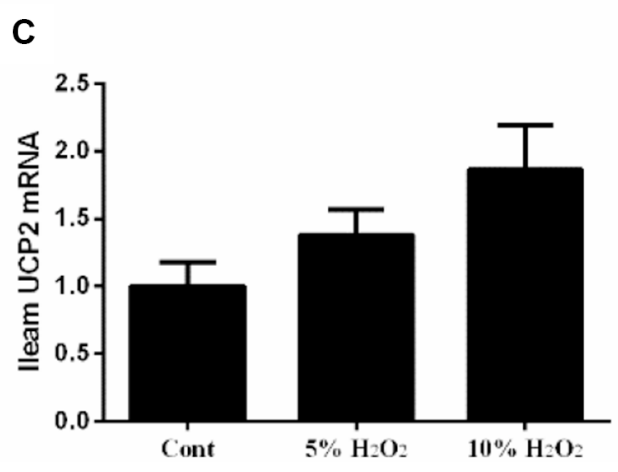

Figure 1: Effects of $\mathrm{H}_{2} \mathrm{O}_{2}$ on UCP2 expression in the duodenum (A), jejunum (B), and ileum $(\mathbf{C})(n=6)$. Data are expressed as the mean \pm standard error of the mean. Values in the same row with different superscripts are significant $(P<0.05)$, while values with same superscripts are not significant different $(P>0.05)$. 

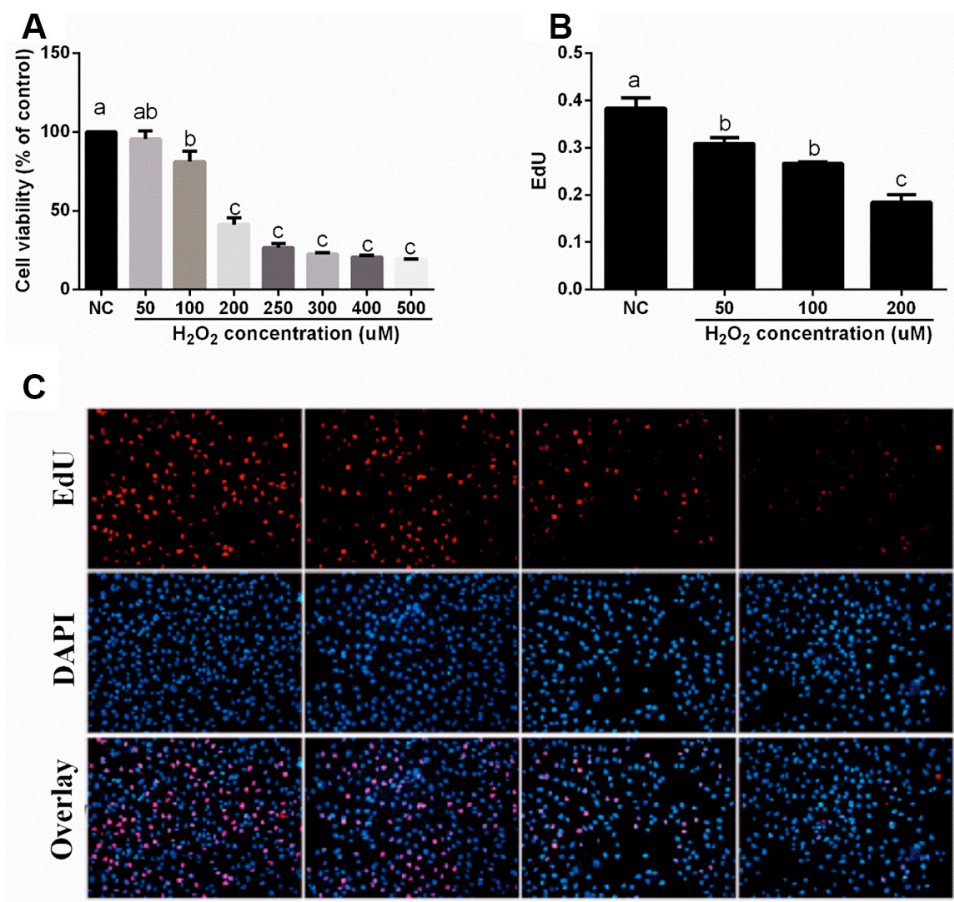

NC

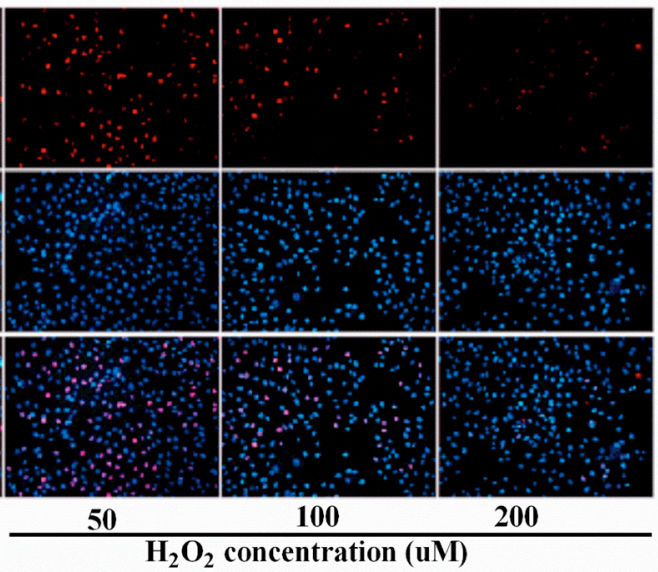

Figure 2: Effects of $\mathrm{H}_{2} \mathrm{O}_{2}$ on cell viability and proliferation in IPEC-J2 cells ( $n=4$ or 6). (A) cell viability (\%); (B) EdU content; and $(\mathbf{C})$ EdU results $(\times 20)$. Data are expressed as the mean \pm standard error of the mean. Values in the same row with different superscripts are significant $(P<0.05)$, while values with same superscripts are not significant different $(P>0.05)$.

A

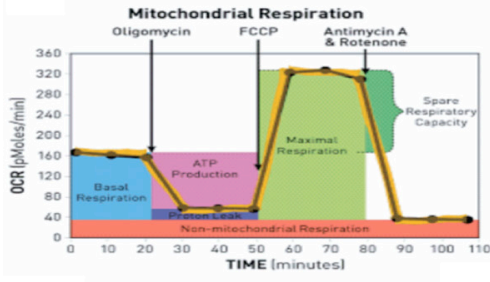

C

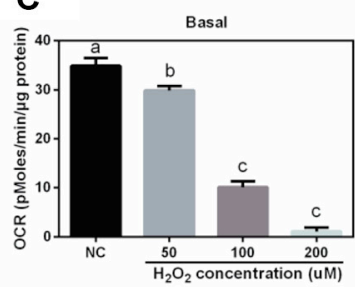

$\mathbf{F}$

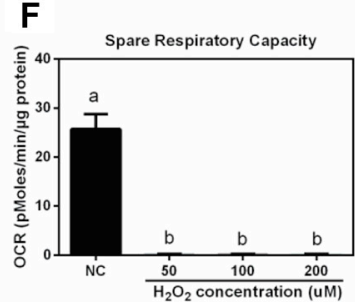

。

G
B
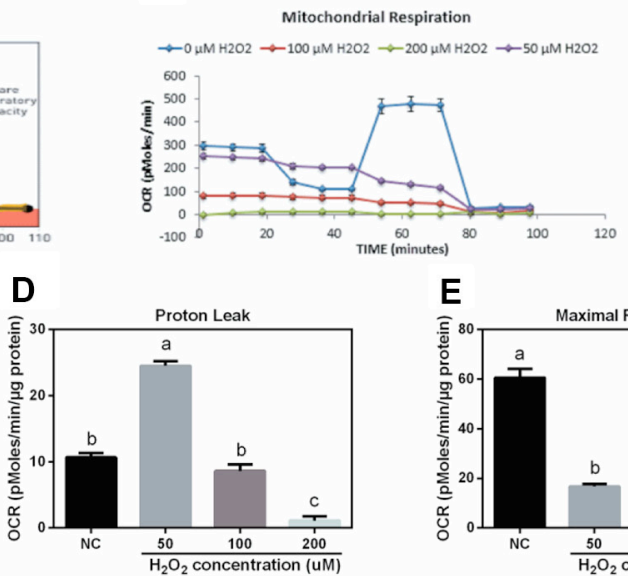

E
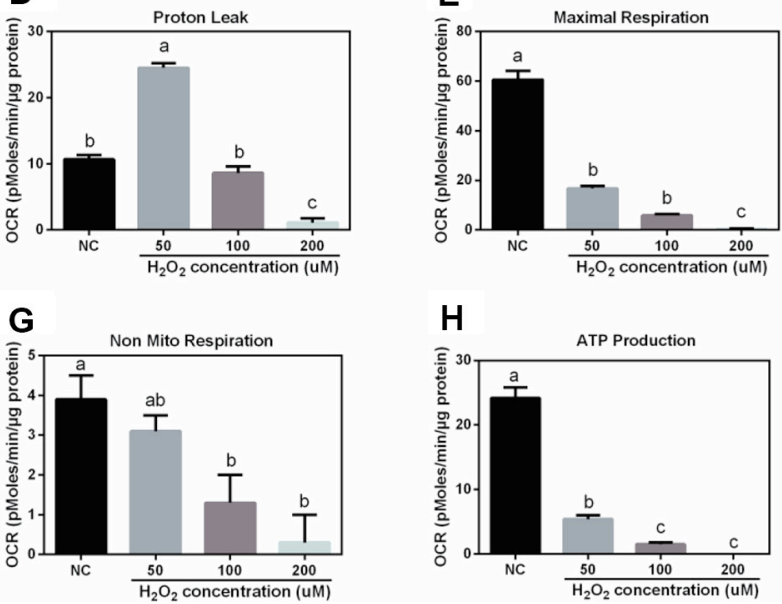

Figure 3: Effects of $\mathrm{H}_{2} \mathrm{O}_{2}$ on mitochondrial respiration in IPEC-J2 cells $(n=4)$. (A) Assay working model; (B) mitochondrial respiration curve; (C) basal respiration; (D) proton leak; (E) maximal respiration; (F) spare respiratory; (G) non-mito respiratory; and (H) ATP production. Data are expressed as the mean \pm standard error of the mean. Values in the same row with different superscripts are significant $(P<0.05)$, while values with same superscripts are not significant different $(P>0.05)$. 
Table 5: Primers used in this study

\begin{tabular}{|c|c|}
\hline Genes & Nucleotide sequence of primers $\left(5^{\prime}-3^{\prime}\right)$ \\
\hline$\beta$-Actin & $\begin{array}{l}\text { F: CTGCGGCATCCACGAAACT } \\
\text { R: AGGGCCGTGATCTCCTTCTG }\end{array}$ \\
\hline $\mathrm{UCP} 2$ & $\begin{array}{l}\text { F: CCAATGTCGCTCGTAATG } \\
\text { R: TGGCAGGGAAGGTCATC }\end{array}$ \\
\hline p53 & $\begin{array}{l}\text { F: CTGCTTCCTGAAAACAACC } \\
\text { R: AAGGGACAAAGGACGACA }\end{array}$ \\
\hline Casp-3 & $\begin{array}{l}\text { F: AGCATCCACATCTGTACCA } \\
\text { R:CCGGAATGGCATGTCGAT }\end{array}$ \\
\hline Casp-8 & $\begin{array}{l}\text { F: TGGGAAAGCATATGAGCTATTCAA } \\
\text { R:TTCCGGAGTCATCTGTGAGTGA }\end{array}$ \\
\hline Bcl-2 & $\begin{array}{l}\text { F: ACGGTGGTGGAGAGACTCTTCA } \\
\text { R:TGACGCTCTCCACACACATGAC }\end{array}$ \\
\hline FasL & $\begin{array}{l}\text { F: AATGGGAAGACACCTATGGAA } \\
\text { R:CTTAGAGCTTATATAAGCCGAAAAACGTC } \\
\text { F: TGCTGGATGCTAACGGATGTC }\end{array}$ \\
\hline TLR1 & R:AAGTGGTTTCAATGTTGTTCAAAGTC \\
\hline TLR2 & $\begin{array}{l}\text { F: TCACTTGTCTAACTTATCATCCTCTTG } \\
\text { R:TCAGCGAAGGTGTCATTATTGC }\end{array}$ \\
\hline TLR3 & $\begin{array}{l}\text { F: AGTAAATGAATCACCCTGCCTAGCA } \\
\text { R:GCCGTTGACAAAACACATAAGGACT }\end{array}$ \\
\hline TLR4 & $\begin{array}{l}\text { F: GCCATCGCTGCTAACATCATC } \\
\text { R:CTCATACTCAAAGATACACCATCGG }\end{array}$ \\
\hline TLR5 & $\begin{array}{l}\text { F: CAGCGACCAAAACAGATTGA } \\
\text { R:TGCTCACCAGACAGACAACC }\end{array}$ \\
\hline TLR6 & $\begin{array}{l}\text { F: AACCTACTGTCATAAGCCTTCATTC } \\
\text { R:GTCTACCACAAATTCACTTTCTTCAG }\end{array}$ \\
\hline TLR7 & $\begin{array}{l}\text { F: TCAGTCAACCGCAAGTTCTG } \\
\text { R:GATGGATCTGTAGGGGAGCA }\end{array}$ \\
\hline TLR8 & $\begin{array}{l}\text { F: AAGACCACCACCAACTTAGCC } \\
\text { R:GACCCTCAGATTCTCATCCATCC }\end{array}$ \\
\hline TLR10 & $\begin{array}{l}\text { F: CACGACAGCCGAATAGCAC } \\
\text { R:GGGAACAGGGAGCAGAGC }\end{array}$ \\
\hline Myd88 & $\begin{array}{l}\text { F: CCTGTCCAACTGCCTCATTTG } \\
\text { R:CTAAGTGTTCTAAGGATGTGTTTCTG }\end{array}$ \\
\hline
\end{tabular}

F: forward; R: reverse.

$\mathrm{H}_{2} \mathrm{O}_{2}$ stimulation might exhibited a feedback regulatory mechanism against oxidative injury via increasing UCP2 expression and mitochondrial proton leak.

\section{MATERIALS AND METHODS}

\section{Animal surgery and experimental design}

Animal surgery was conducted according to our previous report [9]. Briefly, eighteen healthy piglets of similar bodyweight (Landrace $\times$ Large White) (ZhengHong Co., China) were anesthetized (Zoletil 50, Virbac Co., France) and then operated to install a silicone coated latex T-shape catheter (Zhan Jiang Star Enterprism Co., China) in the helicobacter. After surgery, all piglets recovered uneventfully for a week, then randomly divided into three groups $(n=6)$ : a control group in which piglets received an intragastric administration via the T-shape catheter of $10 \mathrm{~mL} / 10 \mathrm{~kg}$ PBS buffer; a $5 \% \mathrm{H}_{2} \mathrm{O}_{2}$ group in which

piglets were given an intragastric administration of 5\% $\mathrm{H}_{2} \mathrm{O}_{2}$; a $10 \% \mathrm{H}_{2} \mathrm{O}_{2}$ group in which piglets received an intragastric administration of $10 \% \mathrm{H}_{2} \mathrm{O}_{2}$ [9]. All piglets were allowed free access to water and feed throughout the experimental period.

All piglets were killed after 7 days. $3 \mathrm{~cm}$ middle duodenum, jejunum, and ileum samples were harvested and immediately frozen in liquid nitrogen for subsequent analyses. This study was approved by the animal welfare committee of the Institute of Subtropical Agriculture, Chinese Academy of Sciences.

\section{cDNA synthesis and quantification mRNA by real-time PCR analysis}

Extraction of total RNA and its reverse transcription were performed according to our previous reports $[10,11]$. Primers were designed with Primer 5.0 according to the gene sequence of pig (http://www.ncbi.nlm.nih.gov/ pubmed/) to produce an amplification product (Table 5). 
$\beta$-actin was used as a housekeeping gene to normalize target gene transcript levels. Real-time PCR was performed according to our previous study [10]. Relative expression was normalized and expressed as a ratio to the expression in control group.

\section{Cell culture}

Intestinal porcine epithelial cells (IPEC-J2) were cultured in serial passage in uncoated plastic culture flasks $\left(100 \mathrm{~mm}^{2}\right)$ in DMEM-H containing $10 \% \mathrm{FBS}$, $5 \mathrm{mM}$ l-glutamine, $100 \mathrm{U} / \mathrm{ml}$ penicillin, and $100 \mu \mathrm{g} / \mathrm{ml}$ streptomycin. Cells were treated with different dosage of $\mathrm{H}_{2} \mathrm{O}_{2}$ to induce oxidative stress. Cell viability was evaluated with the CKK-8 assay (Sigma-Aldrich) according to the manufacturer's instructions. Briefly, $8 \times 10^{3}$ cells were seeded in 96-well plates. The following day, cells were incubated with 50, 100, 200, 250, 300, 400, and $500 \mathrm{uM} \mathrm{H}_{2} \mathrm{O}_{2}$ for 4 hours and then assayed.

\section{EdU (5-Ethynyl -2'- deoxyuridine) measurement}

IPEC-J2 cells cultured in 96-well plates after 96 hour incubation were labeled with $50 \mu \mathrm{M}$ 5-ethynyl2'-deoxyuridine (EdU; Invitrogen) for 1 hour (pulse) before replacing with fresh medium. Cell fixation, permeabilization and EdU detection were performed following manufacturer's instructions for EdU kit (Invitrogen). Cells were measured using an inverted fluorescence microscope (DMI3000B, Leica, Germany).

\section{Mitochondrial respiration}

Mitochondrial respiration after $\mathrm{H}_{2} \mathrm{O}_{2}$ exposure was measured via the XF-24 Extracellular Flux Analyzer and Cell Mito Stress Test Kit. Oligomycin, arbonyl cyanidep-trifluoromethoxyphenylhydrazone (FCCP), rotenone and antimycin A were used to estimate the contribution of non-ATP-linked oxygen consumption (proton leak), ATP-linked mitochondrial oxygen consumption (ATP production), and maximal respiration capacity. The spare respiratory capacity was represented by the maximal respiratory capacity subtracted from the baseline oxygen consumption rate (OCR). The residual oxygen consumption that occurred after addition of rotenone and antimycin A was ascribed to non-mitochondrial respiration and was subtracted from all measured values in the analysis [12]. Total cellular protein was determined and used to normalize mitochondrial respiration rates.

\section{Statistical analysis}

All statistical analyses were performed by using the one-way analysis of variance (ANOVA) to test homogeneity of variances via Levene's test and followed with Tukey's multiple comparison test (SPSS 17.0 software). Data are expressed as the mean \pm standard error of the mean. Values in the same row with different superscripts are significant $(P<0.05)$, while values with same superscripts are not significant different $(P>0.05)$.

\section{ACKNOWLEDGMENTS AND FUNDING}

This study was supported by the National Basic Research Program of China (2013CB127301), National Key R\&D Program (2016YFD0501201), Key Programs of frontier scientific research of the Chinese Academy of Sciences (QYZDY-SSW-SMC008), the National Natural Science Foundation of China (NO. 31272463), Project Supported by Changsha City Science and Technology Program of China (k1508008-21), Hunan Province Key project (2015NK1002) and Hunan Provincial Natural Science Foundation of China (NO. 12JJ2014).

\section{CONFLICTS OF INTEREST}

All authors have no conflicts of interest.

\section{REFERENCES}

1. Mohamadin AM, Ashour OM, El-Sherbeny NA, Alahdal AM, Morsy GM, Abdel-Naim AB. Melatonin protects against hydrogen peroxide-induced gastric injury in rats. Clin Exp Pharmacol Physiol. 2009; 36:367-372.

2. Essick EE, Wilson RM, Pimentel DR, Shimano M, Baid S, Ouchi N, Sam F. Adiponectin modulates oxidative stressinduced autophagy in cardiomyocytes. PLoS One. 2013; 8:e68697.

3. Rao PVLNS, Kiranmayi VS, Swathi P, Jeyseelan L, Suchitra MM, Bitla AR. Comparison Of Two Analytical Methods Used For The Measurement Of Total Antioxidant Status. Journal of antioxidant activity. 2015; 1:22-28.

4. Zhu L, Sun Y, Zhang G, Yu P, Wang Y, Zhang Z. RadicalScavenging And Anti-Oxidative Activities Of TBN In Cell-Free System And Murine H9c2 Cardiomyoblast Cells. Journal of antioxidant activity. 2015; 1:55-68.

5. Yin J, Wu MM, Xiao H, Ren WK, Duan JL, Yang G, Li TJ, Yin YL. Development of an antioxidant system after early weaning in piglets. J Anim Sci. 2014; 92:612-619.

6. Yin J, Ren W, Liu G, Duan J, Yang G, Wu L, Li T, Yin Y. Birth oxidative stress and the development of an antioxidant system in newborn piglets. Free Radic Res. 2013; 47:1027-1035.

7. Yin J, Ren W, Yang G, Duan J, Huang X, Fang R, Li C, Li T, Yin Y, Hou Y, Kim SW, Wu G. 1-Cysteine metabolism and its nutritional implications. Mol Nutr Food Res. 2016; 60:134-146.

8. Yin J, Ren W, Duan J, Wu L, Chen S, Li T, Yin Y, Wu G. Dietary arginine supplementation enhances intestinal expression of SLC7A7 and SLC7A1 and ameliorates growth depression in mycotoxin-challenged pigs. Amino Acids. 2014; 46:883-892. 
9. Yin J, Duan JL, Cui ZJ, Ren WK, Li TJ, Yin YL. Hydrogen peroxide-induced oxidative stress activates NF-kappa B, Nrf2/Keap1 signals and triggers autophagy in piglets. Rsc Adv. 2015; 5:15479-15486.

10. Yin J, Wu M, Duan J, Liu G, Cui Z, Zheng J, Chen S, Ren W, Deng J, Tan X, Al-Dhabi NA, Duraipandiyan V, Liao P, et al. Pyrrolidine Dithiocarbamate Inhibits NF-KappaB Activation and Upregulates the Expression of Gpx1, Gpx4, Occludin, and ZO-1 in DSS-Induced Colitis. Appl Biochem Biotechnol. 2015; 8:1716-1728.

11. Rong Y, Lu Z, Zhang H, Zhang L, Song D, Wang Y. Effects of casein glycomacropeptide supplementation on growth performance, intestinal morphology, intestinal barrier permeability and inflammatory responses in Escherichia coli K88 challenged piglets. Animal Nutrition. 2015; 1:54-59.

12. Tan B, Xiao H, Xiong X, Wang J, Li G, Yin Y, Huang B, Hou Y, Wu G. L-arginine improves DNA synthesis in LPSchallenged enterocytes. Front Biosci (Landmark Ed). 2015; 20:989-1003.

13. Duan JL, Yin J, Ren WK, Wu MM, Chen S, Cui ZJ, Wu X, Huang RL, Li TJ, Yin YL. Pyrrolidine dithiocarbamate restores gastric damages and suppressive autophagy induced by hydrogen peroxide. Free Radic Res. 2015; 49:210-218.

14. Shahandeh A, Purushothuman S, Martin K, Graham M, Johnstone DM, Milward EA. Anti-Oxidant Phytochemicals As Potential Treatments For Age-Related Macular Degeneration. Journal of antioxidant activity. 2015; 1:29-41.

15. Choi A-J, Buisson N, Kim C-T. Digestion characteristics and kinetic analysis of bio-molecules in a simulated human intestinal system. Integr Food Nutr Metab. 2015; 2:189-192.

16. Lavieri R, Piccioli P, Carta S, Delfino L, Castellani P, Rubartelli A. TLR costimulation causes oxidative stress with unbalance of proinflammatory and anti-inflammatory cytokine production. J Immunol. 2014; 192:5373-5381.

17. de Kivit S, Tobin MC, Forsyth CB, Keshavarzian A, Landay AL. Regulation of intestinal immune responses through TLR activation: implications for pro- and prebiotics. Front Immunol. 2014; 5:60.
18. Chen L, Yang S, Zumbrun EE, Guan H, Nagarkatti PS, Nagarkatti M. Resveratrol attenuates lipopolysaccharideinduced acute kidney injury by suppressing inflammation driven by macrophages. Mol Nutr Food Res. 2015; 59:853-864.

19. Da Silva MS, Rudkowska I. Dairy nutrients and their effect on inflammatory profile in molecular studies. Molecular Nutrition \& Food Research. 2015; 59:1249-1263.

20. McCann MJ, Dalziel JE, Bibiloni R, Barnett MPG. An integrated approach to assessing the bio-activity of nutrients in vitro: The anti-oxidant effects of catechin and chlorogenic acid as an example. Integr Food Nutr Metab. 2015; 2:197-204.

21. Murakami S. Role of taurine in the pathogenesis of obesity. Molecular Nutrition \& Food Research. 2015; 59:1353-1363.

22. Kumar S, Appukuttan A, Maghnouj A, Hahn S, Peter Reusch H, Ladilov Y. Suppression of soluble adenylyl cyclase protects smooth muscle cells against oxidative stress-induced apoptosis. Apoptosis. 2014; 19:1069-1079.

23. Ma L, Zhu WZ, Liu TT, Fu HL, Liu ZJ, Yang BW, Song TY, Li GR. H2O2 inhibits proliferation and mediates suppression of migration via DLC1/RhoA signaling in cancer cells. Asian Pac J Cancer Prev. 2015; 16:1637-1642.

24. Hung CH, Chan SH, Chu PM, Tsai KL. Quercetin is a potent anti-atherosclerotic compound by activation of SIRT1 signaling under oxLDL stimulation. Molecular Nutrition \& Food Research. 2015; 59:1905-1917.

25. Diano S, Horvath TL. Mitochondrial uncoupling protein 2 (UCP2) in glucose and lipid metabolism. Trends Mol Med. 2012; 18:52-58.

26. Starkov AA, Andreyev AY, Zhang SF, Starkova NN, Korneeva M, Syromyatnikov M, Popov VN. Scavenging of $\mathrm{H} 2 \mathrm{O} 2$ by mouse brain mitochondria. J Bioenerg Biomembr. 2014; 46:471-477.

27. Ferramosca A, Pinto Provenzano S, Montagna DD, Coppola L, Zara V. Oxidative stress negatively affects human sperm mitochondrial respiration. Urology. 2013; 82:78-83. 